\title{
The DNA damage response in mammalian oocytes
}

\author{
John Carroll ${ }^{1}$ and Petros Marangos ${ }^{2,3} *$ \\ 'School of Biomedical Sciences, Faculty of Medicine, Nursing and Health Sciences, Monash University, Melbourne, VIC, Australia \\ ${ }^{2}$ Department of Biological Applications and Technology, University of loannina, loannina, Greece \\ ${ }^{3}$ Department of Cell and Developmental Biology, University College London, London, UK
}

\section{Edited by:}

Antonio Porro, Ecole Polytechnique

Fédérale de Lausanne, Switzerland

\section{Reviewed by:}

Karla Hutt, Private Health Insurance, Australia

Volker Doetsch, Goethe University, Germany

\section{*Correspondence:}

Petros Marangos, Department of Biological Applications and

Technology, University of loannina, P.O. Box 1186, 45110 loannina, Greece e-mail:pmaragos@cc.uoi.gr
DNA damage is one of the most common insults that challenge all cells. To cope, an elaborate molecular and cellular response has evolved to sense, respond to and correct the damage. This allows the maintenance of DNA fidelity essential for normal cell viability and the prevention of genomic instability that can lead to tumor formation. In the context of oocytes, the impact of DNA damage is not one of tumor formation but of the maintenance of fertility. Mammalian oocytes are particularly vulnerable to DNA damage because physiologically they may lie dormant in the ovary for many years ( $>40$ in humans) until they receive the stimulus to grow and acquire the competence to become fertilized. The implication of this is that in some organisms, such as humans, oocytes face the danger of cumulative genetic damage for decades. Thus, the ability to detect and repair DNA damage is essential to maintain the supply of oocytes necessary for reproduction. Therefore, failure to confront DNA damage in oocytes could cause serious anomalies in the embryo that may be propagated in the form of mutations to the next generation allowing the appearance of hereditary disease. Despite the potential impact of DNA damage on reproductive capacity and genetic fidelity of embryos, the mechanisms available to the oocyte for monitoring and repairing such insults have remained largely unexplored until recently. Here, we review the different aspects of the response to DNA damage in mammalian oocytes. Specifically, we address the oocyte DNA damage response from embryonic life to adulthood and throughout oocyte development.

Keywords: oocytes, DNA damage response, meiotic recombination, p63, DNA damage checkpoint, meiosis, prophase arrest, apoptosis

\section{THE DNA DAMAGE RESPONSE}

Cells respond to DNA damage created in the form of single strand breaks (SSBs) or double strand breaks (DSBs) by arresting their cell cycle to allow time for the damage to be repaired. Therefore, the DNA damage response (DDR) involves cell cycle arrest through the activation of DNA damage checkpoints (DDCs) and DNA damage repair mechanisms. The DDR sequence of events is tightly coordinated so that cell cycle arrest is lifted as soon as the damage has been repaired. When the extent of damage does not allow full repair, programed cell death mechanisms become active in order to remove, through apoptosis, the permanently damaged cells (Bartek and Lukas, 2007; Ciccia and Elledge, 2010).

Eukaryotic cells activate DDR mechanisms primarily at the G1/S-phase transition and the G2/M-phase transition. In both cell cycle phases, DSB or SSB establish a DDC by triggering the activation of the master kinases ATM (ataxia telangiectasia mutated) and ATR (ataxia telangiectasia and Rad3-related), respectively (Reinhardt and Yaffe, 2009; Smith et al., 2010). At G1, the major downstream effector of the ATM/ATR kinases is the transcription factor p53, also known as "the guardian of the genome" (Figure 1; Kastan and Lim, 2000; Bartek et al., 2007). When activated, p53 blocks the transcription of cell cycle regulators that normally induce the G1/S-phase transition, such as cyclin E, while driving the transcription of factors that block the G1/S-phase transition, such as the cyclin-dependent kinase (CDK) inhibitor, p21
(Rocha et al., 2003; Mirzayans etal., 2012). p53 is also the primary inducer of apoptotic mechanisms following DNA damage (Fridman and Lowe, 2003; Meulmeester and Jochemsen, 2008).

At G2, establishment of the DDC and subsequent M-phase entry inhibition requires the ATM/ATR-dependent activation of checkpoint kinases, Chk1 and Chk2 (Figure 2; Bartek and Lukas, 2007; Smith et al., 2010). Normally, entry into M-phase is obtained by the activation of the universal M-phase regulator, cyclin BCDK1 (Doree and Hunt, 2002; Lindqvist et al., 2009). Cyclin $\mathrm{B}-\mathrm{CDK} 1$ activation requires cyclin $\mathrm{B}$ synthesis and the activation of Cdc25 phosphatases which lift CDK1 inhibitory phosphorylations established by CDK1 inhibitors such as Wee1 and Myt1 kinases (Aressy and Ducommun, 2008; Potapova et al., 2009). Following DNA damage at G2, Chk1/Chk2 kinases cause the inhibition of cyclin B-CDK1 activation by disrupting the action of Cdc25 either through facilitating SCF (Skp, Cullin, F-box) ligase-dependent degradation, as in the case of Cdc25A or through inhibitory phosphorylation (Cdc25B, Cdc25C; Mailand et al., 2000; Busino et al., 2003; Ferguson et al., 2005; Boutros et al., 2007).

During the DDC-mediated arrest, DNA damage is repaired by a number of different mechanisms depending on the nature of the damage. Single strand damage is repaired by three main repair pathways: base excision repair (BER), nucleotide excision repair (NER), and mismatch repair (MMR). Two are the major mechanisms involved in DSB repair, namely homologous recombination 


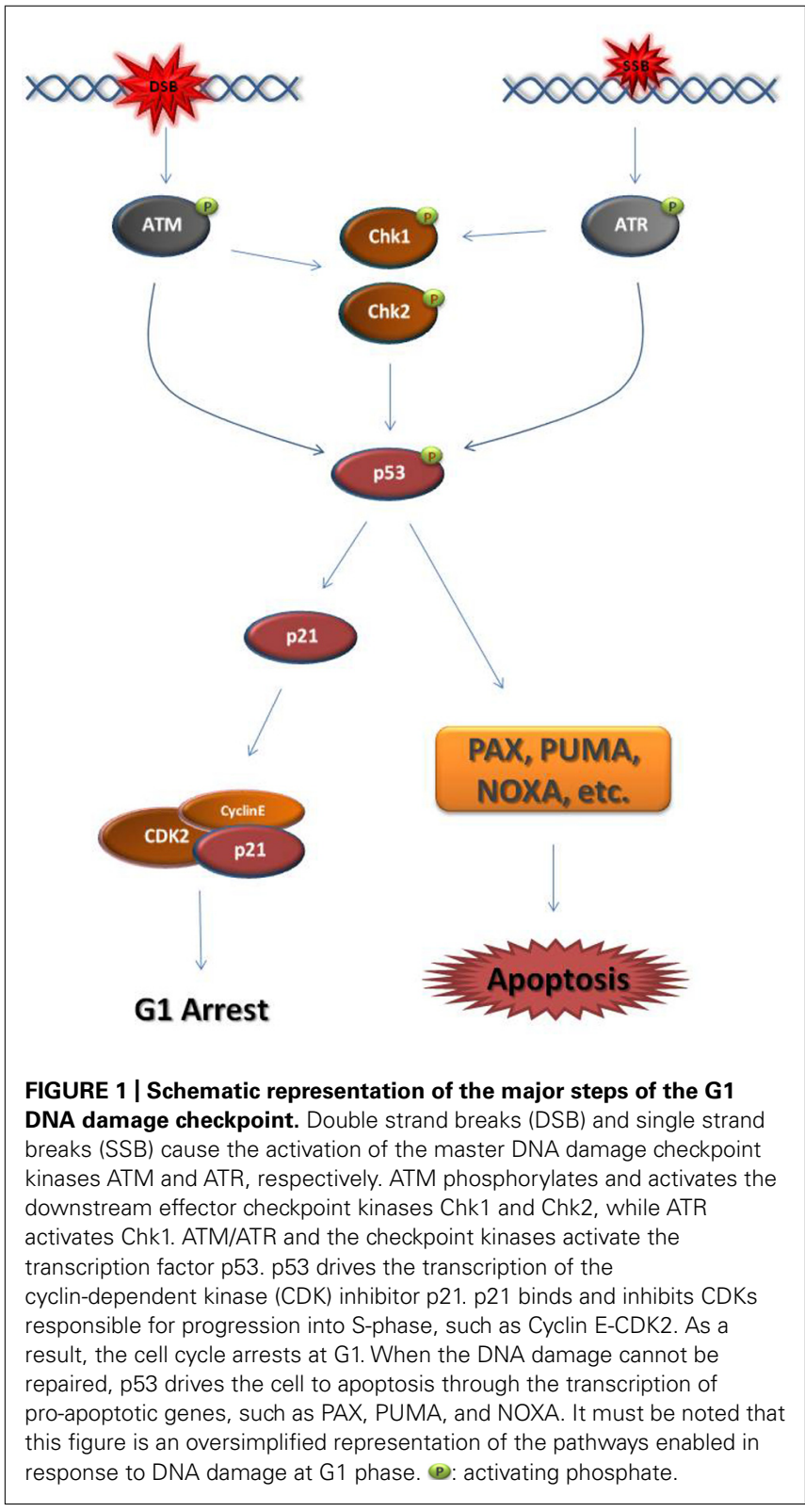

(HR) and non-homologous end joining (NHEJ; Aguilera and Gomez-Gonzalez, 2008; Cohn and D'Andrea, 2008).

\section{PROPHASE ARREST}

The oocyte is a unique cell that differs significantly both from somatic cells but also from the male germ cells in respect to its cell cycle, its functions and its purpose. A unique characteristic of the oocyte, not seen in any other cell type, is prophase arrest.

The mechanisms regulating meiotic prophase arrest and resumption of meiosis resemble the establishment of the somatic cell G2 DDC and checkpoint recovery, respectively (Figures 2 and 3; Bassermann et al., 2008; Solc et al., 2010). The major common element in both systems is the alteration of cyclin B-CDK1 activity, predominantly through the action of CDK1 activators and inhibitors (Bassermann et al., 2008; Solc et al., 2010).

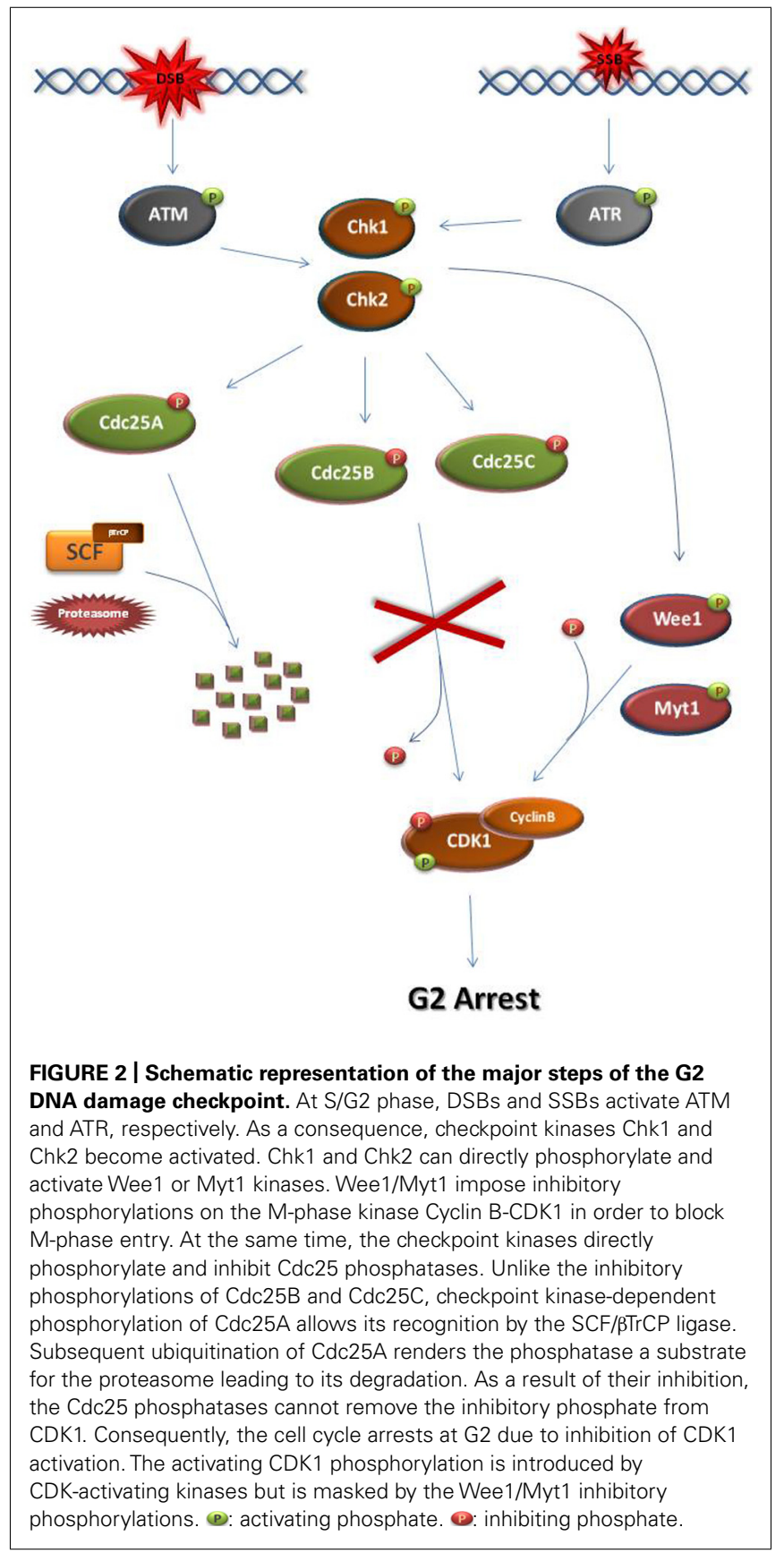

Before the end of gestation oocytes become arrested at the dictyate stage of the meiotic prophase (Rodrigues et al., 2008). During prophase arrest in oocytes, cyclin B-CDK1 remains inactive due to the maintenance of high levels of cAMP within the oocyte and the subsequent sustained activation of protein kinase A (PKA; Figure 3; Mehlmann et al., 2002; Schmitt and Nebreda, 2002). PKA phosphorylates and inactivates the Cdc25 isoform Cdc25B which is responsible for cyclin B-CDK1 activation in oocytes (Lincoln et al., 2002; Pirino et al., 2009; Oh et al., 2010). Furthermore, PKA phosphorylates and activates the CDK1 inhibitor Wee1B which is the oocyte-specific Weel isoform (Han et al., 2005; Oh et al., 2010). Following the rise in the levels of luteinizing hormone 


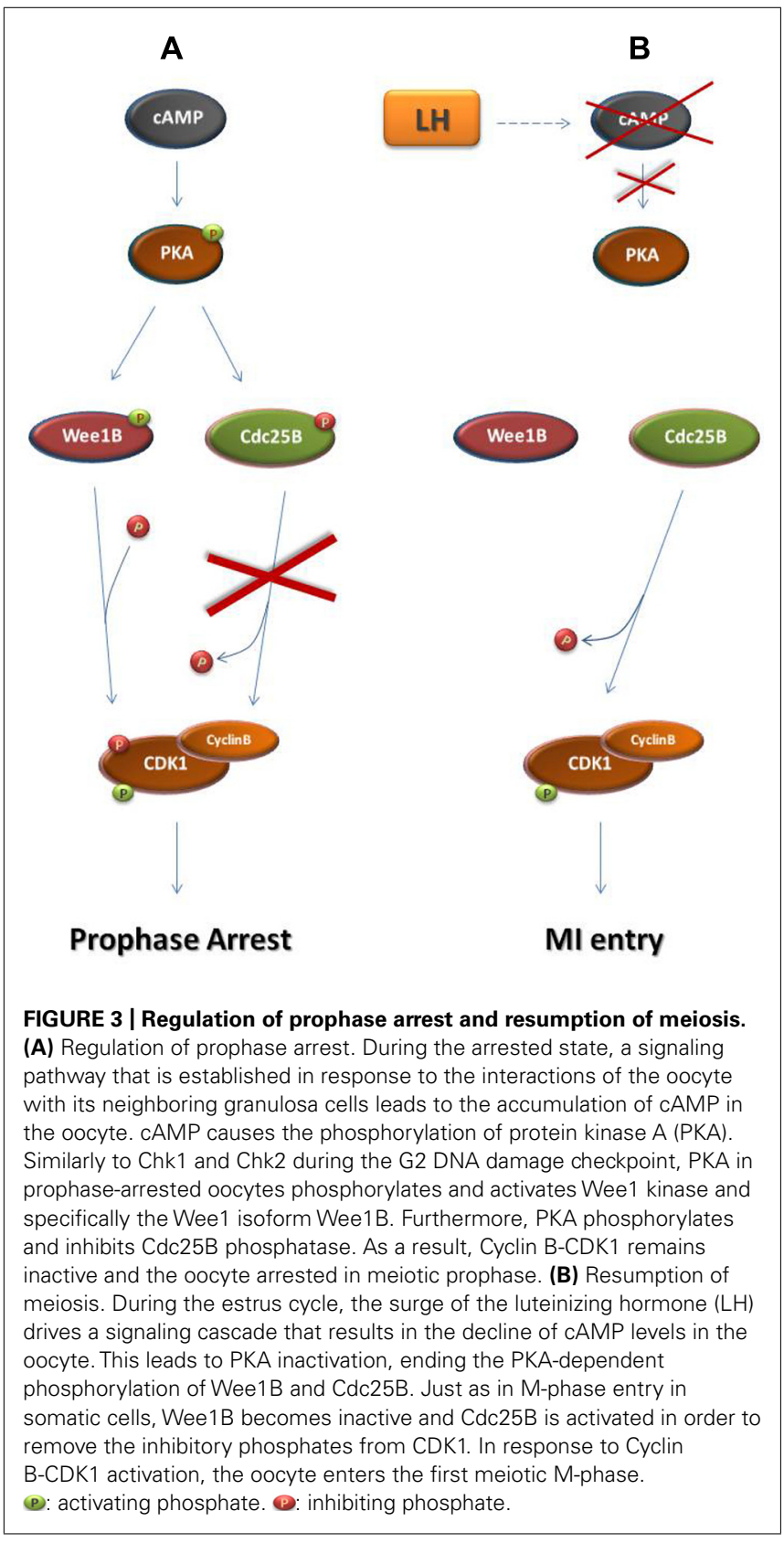

(LH), during the estrus cycle, cAMP levels drop and PKA becomes inactive allowing CDC25B activation and the subsequent cyclin B-CDK1 activation leading to entry into the first meiotic M-phase (MI; Lincoln et al., 2002; Marangos and Carroll, 2004; Solc et al., 2010).

Most of the information we possess regarding the mammalian oocyte DDR involves prophase arrest.

\section{MEIOTIC RECOMBINATION CHECKPOINTS}

In mammalian oocytes, DNA breaks are first identified during meiotic recombination. Meiotic recombination is a process that takes place before birth from the leptotene to the pachytene stage of meiotic prophase and involves the natural formation of DSBs.
Since meiotic recombination processes are extensively reviewed elsewhere (Lydall et al., 1996; Roeder and Bailis, 2000; Burgoyne et al., 2009; Martinez-Perez and Colaiacovo, 2009; Kurahashi et al., 2012) we will limit our analysis to a very general overview of the major aspects of the recombination-induced DDR in mammalian oocytes.

At the start of meiotic prophase (embryonic day 13-18.5 postcoitus in female mice), homologous chromosomes pair along their full length in a process called synapsis (Roeder, 1997; Livera et al., 2008; Martinez-Perez and Colaiacovo, 2009). During synapsis and following the initiation of homolog pairing, DNA DSBs appear within the chromosomes. These DSBs allow DNA exchange between homologous non-sister chromatids through genetic recombination (McDougall et al., 2005; Burgoyne et al., 2009). Recombination leads to the formation of natural bridges, called chiasmata, which hold the homologous chromosomes together until MI allowing their attachment from the opposite poles of the MI spindle and their alignment at the metaphase I plate (McDougall et al., 2005; Burgoyne et al., 2009). Therefore, formation of chiasmata during meiotic recombination ensures the correct segregation of homologous chromosomes during the first meiotic division. Meiotic recombination dysfunctions can cause damaged genomes and the formation of aneuploid gametes (Burgoyne et al., 2009; Yanowitz, 2010; Kurahashi et al., 2012). Therefore, meiotic cells have developed checkpoint mechanisms around the pachytene stage of meiotic prophase in order to ensure the integrity and the completion of recombination (Lydall et al., 1996; Roeder and Bailis, 2000). In mammals, the activation of the recombination pachytene checkpoint when meiotic cells do not complete HR in time leads to cell death through apoptosis (Lydall et al., 1996; Roeder and Bailis, 2000). In oocytes, dysfunction of factors involved in the recombination process leads to apoptosis at the perinatal period (Pittman et al., 1998; Baudat et al., 2000; Di et al., 2005).

In meiotic recombination, it is well established that Spo11 is the main factor to promote the formation of DSBs (Baudat et al., 2000; Di et al., 2005). However, recent findings have shown that homolog pairing is completely abolished in Spo11 $1^{-/-}$ spermatocytes suggesting that Spo11 is also required for the DSBindependent initiation of synapsis (Boateng et al., 2013). Absence of the Spol1-dependent homolog pairing and DSB formation leads to oocyte apoptosis during early follicular development, soon after birth (Baudat et al., 2000; Di et al., 2005). Similar observations are made in mice lacking Spol1-associated proteins, such as Mei4 (Kumar etal., 2010). In Spo11 null mice, the oocytes that survive and acquire the competence to enter M-phase cannot segregate their homologous chromosomes properly due to the absence of chiasmata and remain arrested at MI (Cole et al., 2010).

Other factors, such as ATM and DMC1 are responsible for rejoining the DNA strands (Pittman et al., 1998; Yoshida et al., 1998; Roeder and Bailis, 2000; Di et al., 2005). Besides its role in DDC establishment, ATM is a crucial component of HR repair mechanisms (Smith et al., 2010). The importance of these proteins in DNA strand rejoining is shown by the fact that the absence of DMC1 or ATM leads to programed cell death in prophase oocytes and DMC1 null and ATM null mice are infertile as are Spo11 null mice (Pittman et al., 1998; Yoshida et al., 1998; Baudat et al., 
2000; Di et al., 2005). However, in the case of DMC1 and ATM, the oocytes do not reach the stage of becoming enclosed in follicles and degenerate, through apoptosis earlier than Spo11 null oocytes (Pittman et al., 1998; Yoshida et al., 1998; Baudat et al., 2000; Di et al., 2005). Furthermore, in DMC1-Spo11 and ATMSpo11 double mutants the oocyte reserve depletion phenotype resembles the one seen in Spo11 null mice, which leads to the conclusion that the Spo11 mutation is epistatic to the DMC1 and ATM mutations (Di et al., 2005). These results indicate that, unlike Spo11 mutants, the different phenotype of the DMC1 and ATM mutants is possibly the result of persistent, unrepaired DNA damage.

Besides ATM, other traditional ATM-dependent DDR factors are activated at the sites of meiotic recombination-induced DNA damage in order to amplify the DSB signal, such as ATR kinase, BRCA1 and the phosphorylated form of the nucleosomal histone H2AX ( $\gamma$ H2AX; Xu et al., 2003; Burgoyne et al., 2007). However, in the absence of DSBs, ATR, BRCA1, and $\gamma \mathrm{H} 2 \mathrm{AX}$ are recruited on unsynapsed homologous chromosomes in order to impose their transcriptional silencing (Turner et al., 2005; Mahadevaiah et al., 2008; Burgoyne et al., 2009). If synapsis is not successful, transcriptional silencing can lead to apoptosis if important active genes cease to function (Burgoyne et al., 2009; Kurahashi et al., 2012). This DSB-independent process allows the elimination of oocytes with unsynapsed chromosomes and could explain the Spo11-/oocyte death phenotype.

Therefore, there appear to be two checkpoint responses to recombination defects in oocytes: a DNA DSB-dependent response triggered by unrepaired DSBs and a DNA DSBindependent response triggered by the absence of synapsis. In both cases, the activation of the checkpoint will lead to apoptosis. However, it is not yet determined how unrepaired, recombinationinduced DSBs would trigger apoptosis in oocytes.

\section{p63-DEPENDENT PATHWAY}

In mammalian oocytes, DSBs induced as a consequence of genotoxic stress trigger the activation of a TAp63-dependent mechanism which drives affected oocytes to apoptosis (Suh et al., 2006; Kerr et al., 2012a).

TAp63 is an isoform of p63 which belongs to the p53 family of transcription factors. This protein family includes three transcription factors, namely p53, p63, and p73 (Levine et al., 2011). Besides being important for the activation of DDR mechanisms, mainly cell cycle arrest and apoptosis of damaged cells, these factors also possess a wide range of other functions including their involvement in maternal reproductive efficiency. p53 has been shown to regulate embryo implantation (Hu et al., 2007). TAp73, a p73 isoform, is involved in the M-phase spindle assembly checkpoint and mice lacking TAp73 are infertile. In female TAp $73^{-/-}$mice, infertility is due to chromosome missegregation leading to chromosomal abnormalities in the dividing oocyte and pre-implantation stage embryo (Tomasini et al., 2008; Levine et al., 2011). TAp63, a p63 isoform, is the only p53 family member identified so far to participate in the oocyte DDR. Although, TAp63 is not expressed in the male germ cells, a newly identified hominidae isoform, GTAp63, seems to possess DDR functions in males (Beyer et al., 2011; Amelio et al., 2012).
TAp63 is found in the nucleus of oocytes enclosed in primordial, primary and early pre-antral follicles (Figure 4) but is completely lost in the more mature, antral, follicles (Suh et al., 2006). TAp63 expression begins at embryonic day 18.5 up to adulthood (Suh et al., 2006; Livera et al., 2008). p63 has also been found in human embryonic stage oocytes (Livera et al., 2008). Nevertheless, TAp63 seems to be completely dispensable for oogenesis and the loss of TAp63 does not affect the oocyte reserve. The importance of TAp63 for the oocyte DDR was first identified in TAp63 null mice. In wild type and $\mathrm{p} 53^{-/-}$animals, ionizing radiation causes the complete deterioration and loss of primordial follicles, while the larger pre-antral follicles remain unaffected. However, the oocytes in primordial follicles of the TAp63 null mice were resistant to irradiation and cell death (Suh et al., 2006). These experiments showed that TAp63 induces cell death in primordial follicle oocytes with damaged DNA and that this function is not shared with p53. It must be noted that p63 seems to be only involved in DNA damage-dependent apoptosis since the rate of physiological embryonic oocyte death in $\mathrm{p} 63^{-/-}$ovaries is not different from wild type ovaries (Livera et al., 2008).

It has been proposed that, following DNA damage in oocytes, TAp63 becomes activated through phosphorylation by c-Abl tyrosine kinase (Gonfloni et al., 2009). Gonfloni and colleagues have shown that c-Abl inhibition by imatinib or GNF-2 protected oocytes from apoptosis in response to cisplatin-induced DNA damage (Gonfloni et al., 2009; Maiani et al., 2012). p63 phosphorylation drives resting inactive dimmers to form tetramers which possess the ability to bind DNA and activate the transcription machinery (Deutsch etal., 2011). The possible mechanism for Tap63 activation could involve the DNA damage-induced activation of the stress kinase c-Jun N-terminal kinase (JNK). In somatic cells, JNK phosphorylates the 14-3-3 proteins which under physiological conditions sequester $\mathrm{c}-\mathrm{Abl}$ in the cytoplasm (Yoshida et al., 2005). 14-3-3 phosphorylation releases c-Abl to become transported into the nucleus in order to phosphorylate and activate Tap63. However, there has been some skepticism regarding c-Abl involvement because pharmacological agents, such as imatinib have occasionally been unable to inhibit oocyte apoptosis (Kerr et al., 2012b; Maiani et al., 2012). At the moment, it appears that the controversy surrounding c-Abl would only be resolved conclusively by genetically removing c-Abl from the female germ line.

Another very important question, however, is: which are the transcriptional targets of Tap63 that trigger apoptosis? Recently, two such targets have been identified in mouse oocytes, namely PUMA and NOXA (Kerr et al., 2012c). Both proteins belong to the pro-apoptotic arm of the Bcl-2 family and they have been known to inhibit pro-survival $\mathrm{Bcl}-2$ proteins and promote the function of BAX and BAK, two major pro-apoptotic Bcl-2 family members, which in turn enable the mitochondria-induced apoptosis mechanisms (Chipuk and Green, 2008; Youle and Strasser, 2008). TAp63 enables the transcription of both PUMA and NOXA in mouse primordial follicle oocytes. In addition, $\mathrm{PUMA}^{-/-}$mice and especially the double mutants $\mathrm{PUMA}^{-/-} \mathrm{NOXA}^{-/-}$mice, do not lose their primordial follicle pool in response to genotoxic stress (Kerr et al., 2012c). Therefore, TAp63-dependent PUMA and 
NOXA expression is most possibly responsible for driving oocyte apoptosis following DNA damage.

The knock-out mouse models of TAp63, PUMA and NOXA have shown that inhibition of the TAp63 pathway can rescue the primordial follicle oocyte pool from apoptosis following DNA damage. These observations could open novel medical options in order to sustain the fertility of women undergoing cancer therapy. It is well known that chemotherapy and radiation therapy for treating cancer leads to depletion of the ovarian oocyte reserve and leads to premature ovarian failure (POF) and hence premature menopause (Maltaris et al., 2007). Therefore, possible treatments that are based on the inhibition of the TAp63 pathway could allow the preservation of the oocyte pool following cancer therapy. However, is it safe to allow damaged oocytes to survive following cancer treatment? It would be expected that these oocytes carry significant damage that could be transferred to their offspring. However, an exciting result refutes these concerns: although wild type mice lose their primordial follicle reserve and become infertile following genotoxic stress, $\mathrm{PUMA}^{-/-}$and $\mathrm{PUMA}^{-/-} \mathrm{NOXA}^{-/-}$female mice exposed to ionizing radiation have viable, healthy, and fertile offspring at the same rate as wild type mice not exposed to DNA damage (Kerr et al., 2012c). This finding suggests that during their long prophase arrest, oocytes possess the ability to repair DNA damage efficiently. Although more work needs to be done before treatments are obtained, these observations bring hope to cancer patients facing infertility.

The fact that genotoxic stress does not prevent the preservation of healthy oocytes when the TAp63 pathway is inhibited, raises an interesting question: why is a TAp63-dependent apoptotic pathway needed in oocytes? The answer might lie slightly before TAp63 expression, at the time of meiotic recombination. Quite conveniently, TAp63 is expressed following the physiological recombination-induced DSB repair. Immunofluorescence experiments show that $\gamma \mathrm{H} 2 \mathrm{AX}$ foci representing recombination-induced DSBs do not co-exist with TAp63. In mouse oocytes, $\gamma \mathrm{H} 2 \mathrm{AX}$ staining disappears by E18.5 by which time TAp63 becomes apparent (Livera et al., 2008). In this way, oocytes undergoing meiotic recombination are not in danger of apoptosis. However, as previously discussed, sustained DSBs during recombination, trigger the establishment of oocyte death mechanisms. The activation of these processes during and following the pachytene stage of prophase coincides with the appearance of TAp63. Therefore, TAp63 may

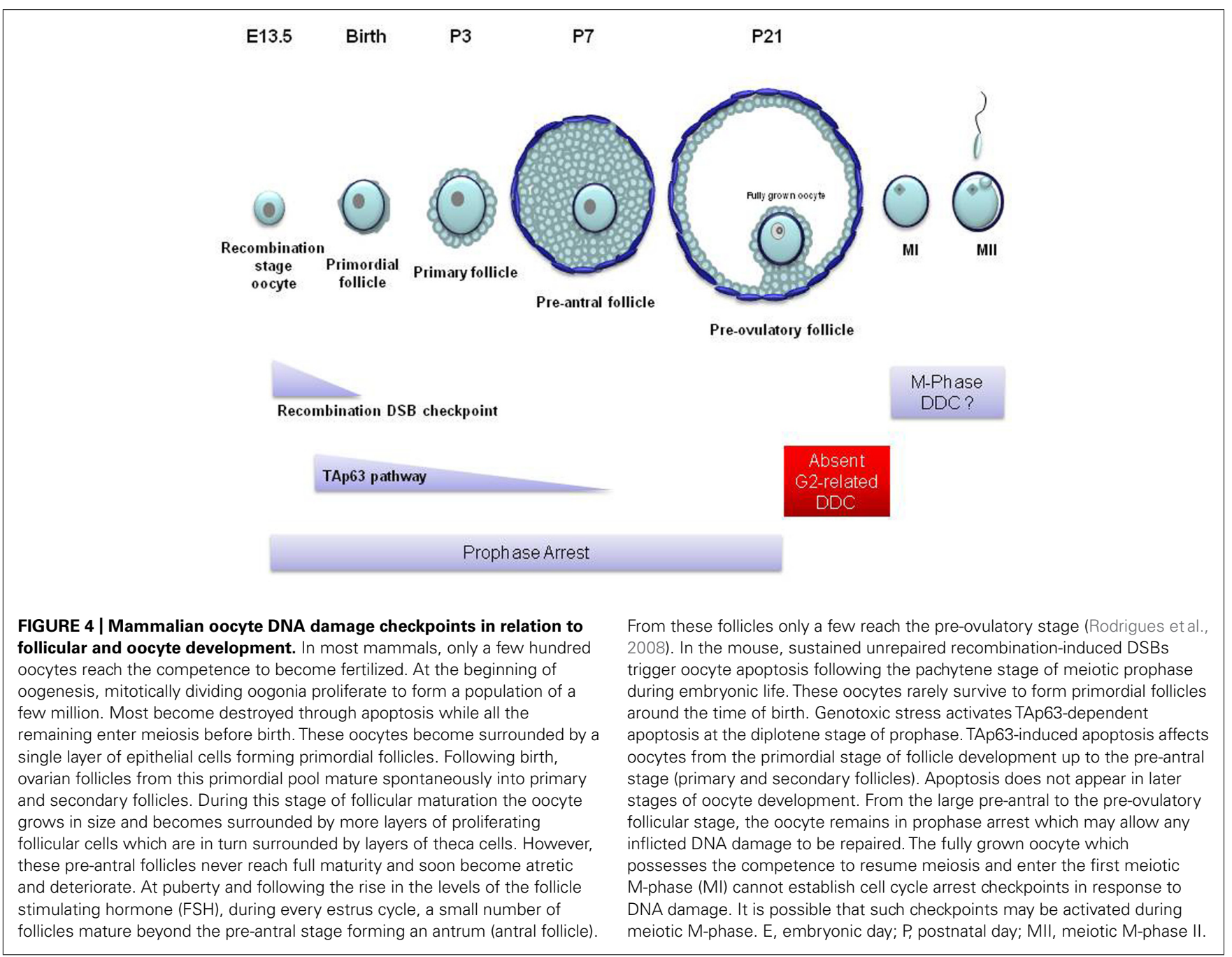


be the "guardian of meiotic recombination," driving to apoptosis any oocytes that fail to rejoin their chromosome arms on time.

These observations support the hypothesis that the original role, in evolutionary terms, of TAp63 may be the protection of the gene pool from meiotic recombination failure and not necessarily from externally inflicted genotoxic insults. Therefore, the deleterious role of TAp63 following exogenous genotoxic stress might be an undesired remnant of a p63-related recombination checkpoint.

At the moment, it remains unknown what processes take place at the late pre-antral follicular stage that would lead to the disappearance of TAp63 and TAp63-dependent apoptosis. Nevertheless, it is a fact that a p63-dependent apoptotic mechanism is absent in antral follicles. Therefore, an important question that arises is how the non-apoptotic mature antral and pre-ovulatory follicles (Figure 4) respond to oocyte DNA damage.

\section{PROPHASE TO MI TRANSITION}

From the antral and up to the pre-ovulatory follicle, the response to DNA damage may involve the activation of repair mechanisms alone. At these stages of follicular development, physiological prophase arrest means that a DNA damage-induced checkpoint is not required to halt the cell cycle in order to permit repair. However, the fully grown oocyte in the pre-ovulatory follicle would not be expected to respond to DNA damage solely by repair mechanisms, but also by cell cycle arrest checkpoints. At this stage, the oocyte has reached full cytoplasmic and nuclear development and has acquired the competence to enter meiotic M-phase as soon as the LH surge occurs (Eppig, 1996). In the mouse, cell cycle regulators that are important for M-phase entry, such as cyclin B, CDK1, and Cdc25 accumulate in the fully grown, pre-ovulatory oocyte (Kanatsu-Shinohara et al., 2000).

Considering the resemblance of meiotic prophase arrest and the G2 DDC, it would be anticipated that fully grown oocytes employ similar DDR mechanisms as the ones present in somatic cell G2 phase. Therefore, it is surprising that a DDC is not established in response to DNA damage in $\mathrm{M}$-phase competent oocytes.

Studies in mouse oocytes have shown that radiation-induced DNA damage may cause chromosomal aberrations, such as aneuploidy, translocations, chromatid interchanges and breaks (Tease, 1983; Jacquet et al., 2005). Past studies hinted at the possibility of a limited DDR in fully grown oocytes (Mailhes et al., 1994; Bradshaw et al., 1995). More specifically, it has been shown that a significant delay in the duration of MI is not observed following injection into female mice of etoposide, a topoisomerase II inhibitor and DSB inducer (Mailhes et al., 1994; Bradshaw et al., 1995).

Recently, the fully grown oocyte DDR has been examined in greater detail. In fully grown oocytes, DNA damage in the form of DSBs, that would normally cause G2 arrest in somatic cells, does not affect the timing and rate of entry into M-phase (Marangos and Carroll, 2012). Although, a DDC is not being established efficiently, DNA damage detection is effective. This has been determined by the presence of $\gamma \mathrm{H} 2 \mathrm{AX}$ at the DSB sites. A DDC is only established following very severe DNA damage inflicted by high concentrations of Etoposide or the DNA intercalating agent Doxorubicin, causing a significant delay in M-phase entry (Marangos and Carroll, 2012). Similar observations were also seen with the use of another DSB-inducing agent Neocarzinostatin (Yuen et al., 2012). Nevertheless, even following severe DNA damage and prolonged arrest, oocytes will eventually enter M-phase. The failure to establish a DDC in prophase-arrested oocytes could be attributed to checkpoint adaptation: a mechanism, which in somatic cells, involves Polo-like kinase 1 (Plk1) and Claspin and leads to the eventual inactivation of the G2 DDC in the presence of irreversible DNA damage (Yoo et al., 2004; Syljuasen et al., 2006).

The molecular basis for the absence of a reliable DDC in response to DSBs appears to be due to a limited ability to activate ATM kinase (Marangos and Carroll, 2012). The lack of ATM activity also affects the activation levels of downstream effectors such as Chk1. Low levels of expression of ATM in fully grown oocytes could be the reason for limited ATM activity. Another possibility could be the distinct chromatin configuration in fully grown oocytes (Marangos and Carroll, 2012). The fully grown oocyte is subjected to chromatin histone modifications such as deacetylation and methylation which are crucial for chromatin condensation and transcriptionally inactive heterochromatin formation (Mattson and Albertini, 1990; De La Fuente, 2006; Ma et al., 2012). Considering that the DDR and ATM specifically are known to be influenced by changes in chromatin structure and chromatin condensation (Bakkenist and Kastan, 2003), one hypothesis might be that DDR mechanisms are either not able to engage or are not triggered due to the fully grown oocyte specialized chromatin configuration.

The induction of Cdc25A degradation and Cdc25B inactivation are also inhibited following DNA damage in fully grown oocytes. The lack of Cdc25A destruction appears to be independent of ATM activity on account of the fact that Cdc25A is still present following high levels of DNA damage when ATM and Chk1 are active. However, the inability of DSBs to block Cdc25B activity seems to be ATM/Chk1-dependent since high levels of DNA damage cause a dramatic inhibitory phosphorylation of the phosphatase (Marangos and Carroll, 2012). Cdc25B inactivation could explain the sustained prophase arrest observed following significant levels of damage. This is not surprising considering that Cdc25B is irreplaceable in oocytes and the absence of Cdc $25 \mathrm{~B}$, as in Cdc $25 \mathrm{~B}$ null mice, leads to female infertility due to the inability of oocytes to enter M-phase (Ferguson et al., 2005).

Besides DSBs, another type of highly toxic DNA lesions, interstrand crosslinks (ICLs), do not appear to activate an efficient DDR. In fully grown mouse oocytes, a major ICL repair factor, the Fanconi Anemia protein FANCD2 fails to be recruited to the sites of the DNA lesions (Yuen et al., 2012). Therefore, ICLs are not being repaired. Nevertheless, the oocytes enter M-phase without any delay. An explanation for these observations could be the possible absence of the activity of the ATM-related kinase, ATR. In somatic cells, ATR and its downstream effector Chk1 become active and enable a checkpoint in response to ICLs (Wang, 2007; Ben-Yehoyada et al., 2009). ATR is also required for the efficient monoubiquitination of FANCD2 enabling its role as an ICL repair factor (Andreassen et al., 2004). It would be interesting to see whether ATR can become active in fully grown oocytes in response to DNA damage. It is possible that, as in the case of ATM, ATR is either not expressed or unable to become recruited to the oocyte 
chromatin. This could explain the absence of FANCD2 and the subsequent inefficiency of the Fanconi Anemia pathway in fully grown oocytes.

It is not yet clear why fully grown oocytes cannot activate major DDR factors, such as ATM or repair factors, such as FANCD2. Although we have provided some possible explanations, further work is necessary in order to understand the mechanisms involved. Irrespective of how the system functions, it may be that oocytes have the capacity to resolve DNA lesions later in the cell cycle, perhaps during MI or MII, or even after fertilization during early embryonic development.

\section{MEIOTIC M-PHASE RESPONSE TO DNA DAMAGE}

When a follicle reaches the pre-ovulatory stage it responds to the surge of $\mathrm{LH}$ and as a result the fully grown oocyte exits prophase arrest and enters MI. Resumption of meiosis leads to the first meiotic division and the extrusion of the first polar body (Pb1) which contains half of the homologous chromosomes and a minimum amount of cytoplasm. The oocyte then enters the second M-phase (MII) without an intervening interphase. It is at this stage the oocyte is ovulated and fertilization takes place. Egg activation triggers the completion of the second meiotic division and entry into the first embryonic cell cycle.

Considering the inability of meiotic prophase to establish a DDC, the two meiotic M-phases pose the only possible line of defense against DNA damage inflicted to the fully grown oocyte before the damage reaches the developing embryo. However, the knowledge on possible meiotic M-phase DDR mechanisms is extremely limited. When fully grown oocytes are exposed to the DSB-inducing agent Neocarzinostatin MI division is blocked (Yuen et al., 2012). It is not yet known, however, how sensitive this

\section{REFERENCES}

Aguilera, A., and Gomez-Gonzalez, B. (2008). Genome instability: a mechanistic view of its causes and consequences. Nat. Rev. Genet. 9, 204-217. doi: 10.1038/nrg2268

Amelio, I., Grespi, F., AnnicchiaricoPetruzzelli, M., and Melino, G. (2012). p63 the guardian of human reproduction. Cell Cycle 11, 45454551. doi: 10.4161/cc.22819

Andreassen, P. R., D'Andrea, A. D., and Taniguchi, T. (2004). ATR couples FANCD2 monoubiquitination to the DNA-damage response. Genes Dev. 18, 1958-1963. doi: 10.1101/gad.1196104

Aressy, B., and Ducommun, B. (2008). Cell cycle control by the CDC25 phosphatases. Anticancer Agents Med. Chem. 8, 818-824. doi: 10.2174/ 187152008786847756

Bakkenist, C. J., and Kastan, M. B. (2003). DNA damage activates ATM through intermolecular autophosphorylation and dimer dissociation. Nature 421, 499-506. doi: 10.1038/ nature 01368

Bartek, J., Bartkova, J., and Lukas, J. (2007). DNA damage signalling guards against activated oncogenes and tumour progression. Oncogene 26, 7773-7779. doi: 10.1038/ sj.onc. 1210881

Bartek, J., and Lukas, J. (2007). DNA damage checkpoints: from initiation to recovery or adaptation. Curr. 10.1016/j.ceb.2007.02.009

Bassermann, F., Frescas, D., Guardavaccaro, D., Busino, L., Peschiaroli, A. and Pagano, M. (2008). The Cdc14BCdh1-Plk1 axis controls the G2 DNA-damage-response checkpoint. Cell 134, 256-267. doi: 10.1016/ j.cell.2008.05.043

Baudat, F., Manova, K., Yuen, J. P., Jasin, M., and Keeney, S. (2000) Chromosome synapsis defects and sexually dimorphic meiotic progression in mice lacking Spol1. Mol. Cell 6, 989-998. doi: 10.1016/S10972765(00)00098-8

Ben-Yehoyada, M., Wang, L. C., Kozekov, I. D., Rizzo, C. J., Gottesman, M. E., and Gautier, J. (2009). Checkpoint signaling from a single DNA interstrand crosslink. Mol. Cell 35, 704-715. doi: 10.1016/ j.molcel.2009.08.014 Opin. Cell Biol. 19, 238-245. doi:

$\mathrm{M}$-phase arrest is and which factors are implicated. Interestingly, the presence of ICLs in either MI or MII does not inhibit or delay cell division. However, ICLs formed in oocytes affect the quality and development of the resulting pre-implantation embryos (Yuen et al., 2012). Therefore, it seems that, the decision to establish or not an M-phase DDC depends on the type of DNA damage. More work needs to be done, in order to clarify the M-phase response to DNA damage.

\section{CONCLUDING REMARKS}

The experimental evidence of especially the last decade has shed light into the diverse ways by which the mammalian oocyte responds to DNA damage. From our current knowledge we can assume that a DDC is necessary, primarily, for avoiding meiotic recombination errors in order to ensure correct chromosome segregation during the meiotic divisions. After birth, the TAp63dependent checkpoint appears to be dispensable. The absence of apoptosis in damaged primordial follicle oocytes is not detrimental probably because the oocytes remain arrested at prophase where they have the time to repair any inflicted DNA damage. However, at the moment when a DDC is mostly needed, when the oocyte acquires the competence to enter $\mathrm{M}$-phase, cell cycle arrest mechanisms that would respond to DNA damage are absent. It seems that the oocytes find preferable for DNA damage to be confronted later, in M-phase or the early embryonic cell cycles. Nonetheless, many important questions are still unanswered: is the recombination DDC a p63-dependent apoptosis mechanism? Why does the fully grown oocyte choose not to activate DDCs? What mechanisms are recruited in meiotic M-phase to respond to DNA damage? Therefore, there are still many pieces to be found in the puzzle that is the DDR of mammalian oocytes.

Beyer, U., Moll-Rocek, J., Moll, U. M., and Dobbelstein, M. (2011). Endogenous retrovirus drives hitherto unknown proapoptotic p63 isoforms in the male germ line of humans and great apes. Proc. Natl. Acad. Sci. U.S.A. 108, 3624-3629. doi: 10.1073/pnas.1016201108

Boateng, K. A., Bellani, M. A., Gregoretti, I. V., Pratto, F., and CameriniOtero, R. D. (2013). Homologous pairing preceding SPO11mediated double-strand breaks in mice. Dev. Cell 24, 196-205. doi: 10.1016/j.devcel.2012.12.002

Boutros, R., Lobjois, V., and Ducommun, B. (2007). CDC25 phosphatases in cancer cells: key players? good targets? Nat. Rev. Cancer 7 , 495-507. doi: 10.1038/nrc2169

Bradshaw, J., Jung, T., Fulka, J. Jr., and Moor, R. M. (1995). UV irradiation of chromosomal DNA and its effect upon MPF and meiosis in mammalian oocytes. Mol. Reprod. Dev. 41, 503-512. doi: 10.1002/ mrd.1080410413

Burgoyne, P. S., Mahadevaiah, S. K., and Turner, J. M. (2007). The management of DNA double-strand breaks in mitotic G2, and in mammalian meiosis viewed from a mitotic G2 perspective. Bioessays 29, 974-986. doi: 10.1002/bies.20639

Burgoyne, P. S., Mahadevaiah, S. K., and Turner, J. M. (2009). The consequences of asynapsis for mammalian meiosis. Nat. Rev. Genet. 10, 207-216. doi: 10.1038/nrg2505

Busino, L., Donzelli, M., Chiesa, M., Guardavaccaro, D., Ganoth, D., Dorrello, N. V., et al. (2003). Degradation of Cdc25A by beta-TrCP during $S$ phase and in response to DNA damage. Nature 426, 87-91. doi: 10.1038 /nature 02082

Chipuk, J. E., and Green, D. R. (2008). How do BCL-2 proteins induce mitochondrial outer membrane permeabilization? Trends Cell Biol. 18, 157164. doi: 10.1016/j.tcb.2008.01.007

Ciccia, A., and Elledge, S. J. (2010). The DNA damage response: making it safe to play with knives. Mol. Cell 40, 179-204. doi: 10.1016/ j.molcel.2010.09.019

Cohn, M. A., and D'Andrea, A. D. (2008). Chromatin recruitment of DNA repair proteins: lessons from the fanconi anemia and 
double-strand break repair pathways. Mol. Cell 32, 306-312. doi: 10.1016/ j.molcel.2008.10.009

Cole, F., Keeney, S., and Jasin, M. (2010). Evolutionary conservation of meiotic DSB proteins: more than just Spo11. Genes Dev. 24, 1201-1207. doi: $10.1101 /$ gad.1944710

De La Fuente, R. (2006). Chromatin modifications in the germinal vesicle (GV) of mammalian oocytes. Dev. Biol. 292, 1-12. doi: 10.1016/ j.ydbio.2006.01.008

Deutsch, G. B., Zielonka, E. M., Coutandin, D., Weber, T. A., Schafer, B., Hannewald, J., et al. (2011). DNA damage in oocytes induces a switch of the quality control factor TAp63alpha from dimer to tetramer. Cell 144, 566-576. doi: 10.1016/ j.cell.2011.01.013

Di, G. M., Barchi, M., Baudat, F., Edelmann, W., Keeney, S., and Jasin, M. (2005). Distinct DNA-damagedependent and -independent responses drive the loss of oocytes in recombination-defective mouse mutants. Proc. Natl. Acad. Sci. U.S.A. 102, 737-742. doi: 10.1073/ pnas.0406212102

Doree, M., and Hunt, T. (2002). From Cdc2 to Cdk1: when did the cell cycle kinase join its cyclin partner? J. Cell Sci. 115, 2461-2464.

Eppig, J. J. (1996). Coordination of nuclear and cytoplasmic oocyte maturation in eutherian mammals. Reprod. Fertil. Dev. 8, 485-489. doi: 10.1071/RD9960485

Ferguson, A. M., White, L. S., Donovan, P. J., and Piwnica-Worms, H. (2005). Normal cell cycle and checkpoint responses in mice and cells lacking Cdc25B and Cdc25C protein phosphatases. Mol. Cell. Biol. 25, 2853 2860. doi: 10.1128/MCB.25.7.28532860.2005

Fridman, J. S., and Lowe, S. W. (2003). Control of apoptosis by p53. Oncogene 22, 9030-9040. doi: 10.1038/sj.onc.1207116

Gonfloni, S., Di, T. L., Caldarola, S., Cannata, S. M., Klinger, F. G., Di, B. C., et al. (2009). Inhibition of the cAbl-TAp63 pathway protects mouse oocytes from chemotherapy-induced death. Nat. Med. 15, 1179-1185. doi: 10.1038/nm.2033

Han, S. J., Chen, R., Paronetto, M. P., and Conti, M. (2005). WeelB is an oocyte-specific kinase involved in the control of meiotic arrest in the mouse. Curr. Biol. 15, 1670-1676. doi: 10.1016/j.cub.2005. 07.056

Hu, W., Feng, Z., Teresky, A. K., and Levine, A. J. (2007). p53 regulates maternal reproduction through
LIF. Nature 450, 721-724. doi: 10.1038 /nature05993

Jacquet, P., Adriaens, I., Buset, J., Neefs, M., and Vankerkom, J. (2005). Cytogenetic studies in mouse oocytes irradiated in vitro at different stages of maturation, by use of an early preantral follicle culture system. Mutat. Res. 583, 168-177. doi: 10.1016/j.mrgentox.2005.03.008

Kanatsu-Shinohara, M., Schultz, R. M., and Kopf, G. S. (2000). Acquisition of meiotic competence in mouse oocytes: absolute amounts of p34(cdc2), cyclin B1, cdc25C, and wee 1 in meiotically incompetent and competent oocytes. Biol. Reprod. 63, 1610-1616. doi: 10.1095/biolreprod63.6.1610

Kastan, M. B., and Lim, D. S. (2000). The many substrates and functions of ATM. Nat. Rev. Mol. Cell Biol. 1, 179-186. doi: 10.1038/35043058

Kerr, J. B., Brogan, L., Myers, M., Hutt, K. J., Mladenovska, T., Ricardo, S., et al. (2012a). The primordial follicle reserve is not renewed after chemical or gamma-irradiation mediated depletion. Reproduction 143, 469476. doi: 10.1530/REP-11-0430

Kerr, J. B., Hutt, K. J., Cook, M., Speed, T. P., Strasser, A., Findlay, J. K., et al. (2012b). Cisplatin-induced primordial follicle oocyte killing and loss of fertility are not prevented by imatinib. Nat. Med. 18, 1170-1172. doi: 10.1038/nm.2889

Kerr, J. B., Hutt, K. J., Michalak, E. M., Cook, M., Vandenberg, C. J., Liew, S. H., et al. (2012c). DNA damageinduced primordial follicle oocyte apoptosis and loss of fertility require TAp63-mediated induction of Puma and Noxa. Mol. Cell 48, 343-352. doi: 10.1016/j.molcel.2012.08.017

Kumar, R., Bourbon, H. M., and de, M. B. (2010). Functional conservation of Mei4 for meiotic DNA doublestrand break formation from yeasts to mice. Genes Dev. 24, 1266-1280. doi: 10.1101/gad.571710

Kurahashi, H., Kogo, H., Tsutsumi, M., Inagaki, H., and Ohye, T. (2012). Failure of homologous synapsis and sex-specific reproduction problems. Front. Genet. 3:112. doi: 10.3389/fgene.2012.00112

Levine, A. J., Tomasini, R., McKeon, F. D., Mak, T. W., and Melino, G. (2011). The p53 family: guardians of maternal reproduction. Nat. Rev. Mol. Cell Biol. 12, 259-265. doi: 10.1038/nrm3086

Lincoln, A. J., Wickramasinghe, D., Stein, P., Schultz, R. M., Palko, M. E., De Miguel, M. P., et al. (2002). $\mathrm{Cdc} 25 \mathrm{~b}$ phosphatase is required for resumption of meiosis during oocyte maturation. Nat. Genet. 30, 446-449. doi: 10.1038/ng856

Lindqvist, A., Rodriguez-Bravo, V., and Medema, R. H. (2009). The decision to enter mitosis: feedback and redundancy in the mitotic entry network. J. Cell Biol. 185, 193-202. doi: 10.1083/jcb.200812045

Livera, G., Petre-Lazar, B., Guerquin, M. J., Trautmann, E., Coffigny, H., and Habert, R. (2008). p63 null mutation protects mouse oocytes from radioinduced apoptosis. Reproduction 135 , 3-12. doi: 10.1530/REP-07-0054

Lydall, D., Nikolsky, Y., Bishop, D. K., and Weinert, T. (1996). A meiotic recombination checkpoint controlled by mitotic checkpoint genes. Nature 383, 840-843. doi: 10.1038/383840a0

Ma, P., Pan, H., Montgomery, R. L., Olson, E. N., and Schultz, R. M. (2012). Compensatory functions of histone deacetylase 1 (HDAC1) and HDAC2 regulate transcription and apoptosis during mouse oocyte development. Proc. Natl. Acad. Sci. U.S.A. 109, E481-E489. doi: 10.1073/ pnas. 1118403109

Mahadevaiah, S. K., Bourc'his, D., de Rooij, D. G., Bestor, T. H. Turner, J. M., and Burgoyne, P. S. (2008). Extensive meiotic asynapsis in mice antagonises meiotic silencing of unsynapsed chromatin and consequently disrupts meiotic sex chromosome inactivation. J. Cell Biol. 182, 263-276. doi: 10.1083/jcb.200 710195

Maiani, E., Di, B. C., Klinger, F. G., Cannata, S. M., Bernardini, S., Chateauvieux, S., et al. (2012) Reply to: cisplatin-induced primordial follicle oocyte killing and loss of fertility are not prevented by imatinib. Nat. Med. 18, 1172-1174. doi: 10.1038/nm.2852

Mailand, N., Falck, J., Lukas, C. Syljuasen, R. G., Welcker, M., Bartek, J., et al. (2000). Rapid destruction of human Cdc25A in response to DNA damage. Science 288, 1425-1429. doi: 10.1126/science.288.5470.1425

Mailhes, J. B., Marchetti, F., Phillips, G. L. Jr., and Barnhill, D. R. (1994). Preferential pericentric lesions and aneuploidy induced in mouse oocytes by the topoisomerase II inhibitor etoposide. Teratog. Carcinog. Mutagen. 14, 39-51. doi: 10.1002/tcm.17701 40106

Maltaris, T., Seufert, R., Fischl, F., Schaffrath, M., Pollow, K., Koelbl, H., et al. (2007). The effect of cancer treatment on female fertility and strategies for preserving fertility. Eur. J. Obstet. Gynecol. Reprod. Biol. 130, 148-155. doi: 10.1016/j.ejogrb.2006. 08.006
Marangos, P., and Carroll, J. (2004) The dynamics of cyclin B1 distribution during meiosis $\mathrm{I}$ in mouse oocytes. Reproduction 128, 153-162. doi: 10.1530/rep.1.00192

Marangos, P., and Carroll, J. (2012). Oocytes progress beyond prophase in the presence of DNA damage. Curr. Biol. 22, 1-6. doi: 10.1016/ j.cub.2012.03.063

Martinez-Perez, E., and Colaiacovo, M. P. (2009). Distribution of meiotic recombination events: talking to your neighbors. Curr. Opin. Genet. Dev. 19, 105-112. doi: 10.1016/ j.gde.2009.02.005

Mattson, B. A., and Albertini, D. F. (1990). Oogenesis: chromatin and microtubule dynamics during meiotic prophase. Mol. Reprod. Dev. 25, 374-383. doi: 10.1002/mrd. 1080250411

McDougall, A., Elliott, D. J., and Hunter, N. (2005). Pairing, connecting, exchanging, pausing and pulling chromosomes. EMBO Rep. 6, 120125. doi: 10.1038/sj.embor.7400331

Mehlmann, L. M., Jones, T. L., and Jaffe, L. A. (2002). Meiotic arrest in the mouse follicle maintained by a Gs protein in the oocyte. Science 297, 1343-1345. doi: 10.1126/science. 1073978

Meulmeester, E., and Jochemsen, A. G. (2008). p53: a guide to apoptosis. Curr. Cancer Drug Targets 8, 87-97. doi: 10.2174/156800908783769337

Mirzayans, R., Andrais, B., Scott, A., and Murray, D. (2012). New insights into p53 signaling and cancer cell response to DNA damage: implications for cancer therapy. J. Biomed. Biotechnol. 2012, 170325. doi: 10.1155/2012/170325

Oh, J. S., Han, S. J., and Conti, M. (2010). Wee1B, Myt1, and Cdc25 function in distinct compartments of the mouse oocyte to control meiotic resumption. J. Cell Biol. 188, 199-207. doi: 10.1083/jcb. 200907161

Pirino, G., Wescott, M. P., and Donovan, P. J. (2009). Protein kinase A regulates resumption of meiosis by phosphorylation of Cdc25B in mammalian oocytes. Cell Cycle 8, 665-670. doi: 10.4161/cc.8.4.7846

Pittman, D. L., Cobb, J., Schimenti, K. J., Wilson, L. A., Cooper, D. M., Brignull, E., et al. (1998). Meiotic prophase arrest with failure of chromosome synapsis in mice deficient for Dmc1, a germline-specific RecA homolog. Mol. Cell 1, 697-705. doi: 10.1016/S1097-2765(00)80069-6

Potapova, T. A., Daum, J. R., Byrd, K. S., and Gorbsky, G. J. (2009). Fine tuning the cell cycle: activation 
of the Cdk1 inhibitory phosphorylation pathway during mitotic exit. Mol. Biol. Cell 20, 1737-1748. doi: 10.1091/mbc.E08-07-0771

Reinhardt, H. C., and Yaffe, M. B. (2009). Kinases that control the cell cycle in response to DNA damage: Chk1, Chk2, and MK2. Curr. Opin. Cell Biol. 21, 245-255. doi: 10.1016/j.ceb.2009.01.018

Rocha, S., Martin, A. M., Meek, D. W., and Perkins, N. D. (2003). p53 represses cyclin D1 transcription through down regulation of $\mathrm{Bcl}-3$ and inducing increased association of the p52 NF-kappaB subunit with histone deacetylase 1. Mol. Cell. Biol. 23, 47134727. doi: 10.1128/MCB.23.13.47134727.2003

Rodrigues, P., Limback, D., McGinnis, L. K., Plancha, C. E., and Albertini, D. F. (2008). Oogenesis: prospects and challenges for the future. $J$. Cell. Physiol. 216, 355-365. doi: 10.1002/jcp. 21473

Roeder, G. S. (1997). Meiotic chromosomes: it takes two to tango. Genes Dev. 11, 2600-2621. doi: 10.1101/gad.11.20.2600

Roeder, G. S., and Bailis, J. M. (2000). The pachytene checkpoint. Trends Genet. 16, 395403. doi: 10.1016/S0168-9525(00) 02080-1

Schmitt, A., and Nebreda, A. R. (2002). Inhibition of Xenopus oocyte meiotic maturation by catalytically inactive protein kinase A. Proc. Natl. Acad. Sci. U.S.A. 99, 4361-4366. doi: 10.1073/pnas.022056399

Smith, J., Tho, L. M., Xu, N., and Gillespie, D. A. (2010). The
ATM-Chk2 and ATR-Chk1 pathways in DNA damage signaling and cancer. Adv. Cancer Res. 108, 73-112. doi: 10.1016/B978-0-12380888-2.00003-0

Solc, P., Schultz, R. M., and Motlik, J. (2010). Prophase I arrest and progression to metaphase I in mouse oocytes: comparison of resumption of meiosis and recovery from G2-arrest in somatic cells. Mol. Hum. Reprod. 16, 654-664. doi: 10.1093/molehr/gaq034

Suh, E. K., Yang, A., Kettenbach, A., Bamberger, C., Michaelis, A. H., Zhu, Z., et al. (2006). p63 protects the female germ line during meiotic arrest. Nature 444, 624-628. doi: 10.1038/nature05337

Syljuasen, R. G., Jensen, S., Bartek, J., and Lukas, J. (2006). Adaptation to the ionizing radiation-induced G2 checkpoint occurs in human cells and depends on checkpoint kinase 1 and Polo-like kinase 1 kinases. Cancer Res. 66, 10253-10257. doi: 10.1158/00085472.CAN-06-2144

Tease, C. (1983). X-ray-induced chromosome aberrations in dictyate oocytes of young and old female mice. Mutat. Res. 119, 191-194. doi: 10.1016/0165-7992(83)90128-8

Tomasini, R., Tsuchihara, K., Wilhelm, M., Fujitani, M., Rufini, A., Cheung, C. C., et al. (2008). TAp73 knockout shows genomic instability with infertility and tumor suppressor functions. Genes Dev. 22, 2677-2691. doi: 10.1101/gad.1695308

Turner, J. M., Mahadevaiah, S. K., Fernandez-Capetillo, O., Nussenzweig, A., $\mathrm{Xu}, \mathrm{X}$., Deng, C. X., et al. (2005). Silencing of unsynapsed meiotic chromosomes in the mouse. Nat. Genet. 37, 41-47. doi: $10.1038 / \mathrm{ng} 1484$

Wang, W. (2007). Emergence of a DNAdamage response network consisting of Fanconi anaemia and BRCA proteins. Nat. Rev. Genet. 8, 735-748. doi: 10.1038/nrg2159

$\mathrm{Xu}, \mathrm{X} .$, Aprelikova, O., Moens, P., Deng, C. X., and Furth, P. A. (2003). Impaired meiotic DNAdamage repair and lack of crossing over during spermatogenesis in BRCA1 full-length isoform deficient mice. Development 130, 2001-2012. doi: 10.1242/dev.00410

Yanowitz, J. (2010). Meiosis: making a break for it. Curr. Opin. Cell Biol. 22, 744-751. doi: 10.1016/ j.ceb.2010.08.016

Yoo, H. Y., Kumagai, A., Shevchenko, A., Shevchenko, A., and Dunphy, W. G. (2004). Adaptation of a DNA replication checkpoint response depends upon inactivation of Claspin by the Polo-like kinase. Cell 117, 575-588. doi: 10.1016/S00928674(04)00417-9

Yoshida, K., Kondoh, G., Matsuda, Y., Habu, T., Nishimune, Y., and Morita, T. (1998). The mouse RecAlike gene $\mathrm{Dmcl}$ is required for homologous chromosome synapsis during meiosis. Mol. Cell 1, 707718. doi: 10.1016/S1097-2765(00) 80070-2

Yoshida, K., Yamaguchi, T., Natsume, T., Kufe, D., and Miki, Y. (2005). JNK phosphorylation of 14-3-3 proteins regulates nuclear targeting of $\mathrm{c}-\mathrm{Abl}$ in the apoptotic response to DNA damage. Nat. Cell Biol. 7, 278-285. doi: $10.1038 /$ ncb 1228
Youle, R. J., and Strasser, A. (2008). The BCL-2 protein family: opposing activities that mediate cell death. Nat. Rev. Mol. Cell Biol. 9, 47-59. doi: 10.1038/nrm2308

Yuen, W. S., Merriman, J. A., O'Bryan, M. K., and Jones, K. T. (2012). DNA double strand breaks but not interstrand crosslinks prevent progress through meiosis in fully grown mouse oocytes. PLOS ONE 7:e43875. doi: 10.1371/journal.pone. 0043875

Conflict of Interest Statement: The authors declare that the research was conducted in the absence of any commercial or financial relationships that could be construed as a potential conflict of interest.

Received: 05 April 2013; paper pending published: 23 April 2013; accepted: 03 June 2013; published online: 24 June 2013.

Citation: Carroll $J$ and Marangos $P$ (2013) The DNA damage response in mammalian oocytes. Front. Genet. 4:117. doi: 10.3389/fgene.2013.00117

This article was submitted to Frontiers in Cancer Genetics, a specialty of Frontiers in Genetics.

Copyright (c) 2013 Carroll and Marangos. This is an open-access article distributed under the terms of the Creative Commons Attribution License, which permits use, distribution and reproduction in other forums, provided the original authors and source are credited and subject to any copyright notices concerning any third-party graphics etc. 